\title{
Animais Reais e Virtuais no Sul do Brasil: Atitudes e Práticas Laboratoriais ${ }^{1}$
}

\author{
Ebenézer A. de Oliveira ${ }^{2}$ \\ Malone College, OH, E.U.A. \\ Giana B. Frizzo \\ Universidade Federal de Santa Maria
}

\begin{abstract}
RESUMO - Examinamos as práticas de pesquisa e ensino, comparadas às atitudes dos docentes de psicologia sul-brasileiros quanto à ética, a legislação e os custos de pesquisa e ensino com animais, e quanto ao uso de simuladores computadorizados. Examinamos ainda o papel de fatores demográficos na variância das atitudes. Dentre os resultados, destaca-se que os sulbrasileiros (especialmente, os homens) são unanimemente favoráveis à pesquisa animal. A produção científica relatada foi baixa, sugerindo discrepância entre atitudes e práticas de pesquisa animal. A amostra foi também favorável ao uso de animais reais e virtuais no ensino, embora preferindo os primeiros, o que refletiu na prática. Quanto mais jovens os participantes, mais favorável sua atitude para com o uso de animais reais; e quanto maior seu nível de instrução, mais favorável sua atitude para com o uso de animais virtuais. Esses e outros resultados foram discutidos à luz do vigente debate internacional sobre práticas laboratoriais com animais.
\end{abstract}

Palavras-chave: ensino de psicologia; ética; legislação; psicologia experimental; informática.

\section{Real and Virtual Animals in Southern Brazil: Attitudes and Lab Practices}

\begin{abstract}
We examined the teaching and research practices, as compared to the attitudes of Southern-Brazilian professors of psychology toward the ethics, legislation, and costs of research and teaching with animals, and toward the alternative use of computerized simulators. We also examined the role of demographic factors in the variance of selected attitudes. The results showed that Southern Brazilians (especially males) are unanimously in favor of animal research. Participants reported a low scientific production, suggesting discrepancy between practices and attitudes toward animal research. The sample was also favorable to the use of both real and virtual animals in undergraduate teaching, although prefering the former, which reflected in the practice. The younger the participants, the more favorable their attitude toward the use of real animals; and the higher their level of instruction, the more favorable their attitude toward the use of virtual animals. These and other results were discussed in light of the current international debate on the lab practices with animals.
\end{abstract}

Key words: teaching of psychology; ethics; legislation; experimental psychology; information science.

Por motivos éticos, legais, financeiros ou teóricos, o uso de animais ${ }^{3}$ laboratoriais na pesquisa e no ensino de psicologia vem declinando nos últimos anos. Thomas e Blackman (1992) relataram uma queda da ordem de $70 \%$ no uso de animais pelos departamentos de psicologia britânicos, des-

1 Nossa gratidão aos colegas que participaram voluntariamente dessa pesquisa, aos Conselhos Regionais de Psicologia-Regiões 7, 8 e 12, pela ajuda na seleção da amostra, e à Pró-Reitoria de Pós-graduação e Pesquisa da UFSM pelo apoio financeiro através do Fundo de Incentivo à Pesquisa-FIPE. Pesquisa apoiada pelo CNPq, nas formas de bolsa de produtividade do primeiro autor e bolsa de iniciação científica da segunda autora. Uma versão preliminar deste artigo foi apresentada pelo primeiro autor na $107^{\text {th }}$ Annual Convention of the American Psychological Association, em Boston, MA, E.U.A., em agosto de 1999.

2 Endereço : Department of Psychology, Malone College. $51525^{\text {th }}$ Street NW. Canton, OH, E.U.A. E-mail: edeoliveira@malone.edu

3 Animais não humanos; empregamos o adjetivo reais apenas quando é preciso distinguir dos animais virtuais, de simuladores computadorizados, no contexto imediato. de 1977, e atribuíram esse fenômeno à crescente relutância dos estudantes universitários em participar de aulas práticas ou projetos de pesquisa que envolvem animais. Segundo esses pesquisadores, mesmo estudos estritamente observacionais, sem sofrimento para os animais participantes, são vistos com reservas, e "alguns estudantes têm se sentido tão desconfortáveis sobre a questão ética de trabalhar com animais, que evitam comentar em suas monografias a respeito de dados relevantes obtidos por estudos com animais" (p. 1679).

Essa mesma tendência tem sido registrada na Itália, Suíça, Canadá e Estados Unidos da América, estimando-se uma queda entre 30 e $50 \%$ no uso de animais experimentais nos últimos 20 anos (Rowan \& Loew, 1995). Nos Estados Unidos, ativistas em defesa dos animais opõem-se à prática experimental com não-humanos não mais por meio de manifestações pacíficas, com faixas e cartazes; agora, eles invadem laboratórios para soltar os animais e danificar equipamentos, ameaçam e até agridem os cientistas responsáveis. Uma série de tais acontecimentos vêm se alastrando em grandes centros de ensino e pesquisa daquele país, inclusive nas 
conceituadas universidades de Rochester, Harvard e Minnesota, deixando estudantes, professores e pesquisadores da psicologia animal em estado de choque (Azar, 1999; Overmier, 1999; Rivera, 1999).

No Brasil, Hunziker (1995) relata que, de 1971 a 1994, a proporção dos trabalhos de pós-graduação com animais no Instituto de Psicologia da Universidade de São Paulo (IPUSP) caiu de $66 \%$ para $32,8 \%$. E, no ensino de graduação em psicologia, das 50 disciplinas obrigatórias, apenas uma (Psicologia Experimental I) empregava o trabalho direto com animais. Contudo, além de restritos a uma única instituição, esses índices podem estar subestimando o uso didático-científico de animais, pois enfocam uma única área específica, qual seja, a de Análise Experimental do Comportamento, excluindo, portanto, o ensino e a pesquisa em outras áreas, como a Etologia, a Psicologia Evolucionária e a Neurociência.

Hunziker (1995) especulou que a política dos direitos animais não estaria ligada aos resultados da sua pesquisa, ao contrário do que se observa em países europeus e norte-americanos. É bem possível que, como alega esta pesquisadora, o movimento de defesa animal não tenha inflamado tanto os ânimos dos brasileiros como fez na Europa e nos Estados Unidos, e que considerações teóricas mentalistas e humanistas sejam as principais responsáveis pelo alegado declínio na prática laboratorial com animais no Brasil. Embora plausível, esse argumento ainda aguarda respaldo empírico, e não há pesquisa informando sobre as atitudes dos psicólogos experimentais brasileiros quanto à relevância do experimento animal na pesquisa e no ensino de psicologia, ou quanto à qualidade do tratamento recebido por esses animais, ou ainda quanto às leis reguladoras e ao financiamento dessa prática no país. O presente estudo busca explorar alguns aspectos éticos, legais e financeiros da prática experimental com animais, bem como a alternativa tecnológica que emprega animais virtuais.

\section{A Questão Ética}

O Artigo 30, seção $b$ do Código de Ética Profissional dos Psicólogos (Conselho Federal de Psicologia, 1995) veda ao Psicólogo a promoção de "atividades que envolvam qualquer espécie de risco ou prejuízo a seres humanos ou sofrimentos desnecessários para animais (p. 108)." Portanto, presume-se que haja um esforço do profissional para evitar procedimentos desnecessariamente penosos para os animais. A dificuldade, porém, está em se estabelecer quais procedimentos seriam considerados demasiadamente estressantes ou dolorosos nos animais, e em que circunstâncias seriam tais procedimentos desnecessários e, portanto, eticamente inadmissíveis.

Comitês técnicos debatem entre si sobre que tipos de atividades são consideradas estressantes ou dolorosas, levando-se em conta a espécie animal, pois há diferenças filogenéticas com relação aos níveis de tolerância (Orlans, 1993). A American Psychological Association vincula a questão do sofrimento ao propósito do experimento, pois estipula que o procedimento experimental deve ter um claro propósito científico que se traduz em "resultados que beneficiam a saúde ou o bem-estar dos seres humanos ou de outros animais" (APA Guidelines for Ethical Conduct in the Care and Use of Animals, Section VI.A; 1992). Uma vez assegurados os benefícios didáticos ou científicos, seriam admissíveis procedimentos dolorosos, e até altamente estressantes ou invasivos (e.g., choque elétrico, radiação, injeção de drogas), desde que realizados por profissional competente ou por estudante sob supervisão e em local físico adequado (Plous, 1996).

De fato, na maior parte da pesquisa animal, facilmente se reconhecem os benefícios para a humanidade. Juntos, roedores e aves perfazem $90 \%$ dos animais laboratoriais na psicologia (APA Science Directorate, s.d.), e, graças a eles, temos hoje um melhor conhecimento dos sistemas básicos de aprendizagem e motivacional (fome, sede, reprodução), bem como dos processos psicológicos da drogadição, da tolerância e dos efeitos de retirada (withdrawal) de uma variedade de drogas, inclusive álcool, cafeína, benzodiazepinas e outras (Hollis, 1997). Desnecessário dizer que tal conhecimento se traduz em intervenções psicológicas que beneficiam muitos seres humanos - ex.: psicoterapia do alcoolismo baseada no contracondicionamento aversivo. As exigências de participantes com um ciclo vital curto e de freqüente monitoração, somadas aos riscos de efeitos colaterais, no caso dos estudos psicofarmacológicos, desestimulam o uso de seres humanos nesses procedimentos experimentais.

Contudo, os benefícios para a humanidade da prática experimental com animais nem sempre são tão evidentes, e os procedimentos adotados terminam sendo eticamente difíceis de justificar. Greek e Greek (1999) apresentam vários exemplos de pesquisas com chimpanzés, cujos resultados não podem ser extrapolados aos seres humanos. PCP (vulgarmente conhecida como "pó de anjo") e Nitrobenzina estão na lista de drogas que se mostraram tóxicas em seres humanos (em alguns casos, provocando a morte) após terem sido testadas com segurança em chimpanzés. Nesses casos, dificilmente se poderia justificar a privação da liberdade e a penosa rotina a que se submetem esses animais laboratoriais.

\section{A Questão Legal}

O mau trato de animais, ainda que em nome do avanço científico, também assume uma dimensão legal em muitos países, especialmente nos mais desenvolvidos. Via de regra, a lei reflete preocupações da população com relação ao bemestar dos animais. Por exemplo, a lei britânica que restringe o uso de animais laboratoriais reflete a mentalidade do povo. Em 1990, uma pesquisa de opinião pública Gallup (Man's Mirror, conforme citado por Plous, 1996) no Reino Unido revelou que $50 \%$ dos cidadãos achavam que experimentos com animais deveriam ser banidos, ou legalmente mais restritos. Esse índice supera o de desaprovação da pornografia, do aborto e da pena capital naquele país.

O quadro brasileiro é bem diferente. Até recentemente, as leis que regulavam a prática didático-científica eram ain- 
da esparsas e de difícil aplicação, e não dispunham claramente sobre experimentos com animais. A Lei Federal 9.605, de 12 de fevereiro de 1998, tentou corrigir um pouco essas falhas. No Capítulo V, Seção I, que trata especificamente dos crimes contra a fauna, o Art. 32 considera crime "praticar ato de abuso, maus tratos, ferir ou mutilar animais silvestres, domésticos ou domesticados, nativos ou exóticos" (Diário Oficial da União, 13/02/1998, p. 1). A pena prevista é de 3 meses a um ano de reclusão e multa. O Parágrafo Primeiro especifica: "Incorre nas mesmas penas quem realiza experiência dolorosa ou cruel em animais vivos, ainda que para fins didáticos ou científicos, quando existirem recursos alternativos." Embora seja crucial o avanço no sentido de prever penas aos infratores e incentivar a busca de recursos alternativos por docentes e pesquisadores, o texto da lei não esclarece sobre quais animais são por ele amparados, e deixa margem para múltiplas interpretações sobre o que constitui abuso ou mau trato.

\section{A Questão Financeira}

Além dos aspectos ético e legal, o experimento com animais traz preocupações financeiras para as instituições de ensino e pesquisa. A literatura consultada não informa sobre o custo anual médio da manutenção de um biotério e de um laboratório onde se trabalha com animais, no Brasil. Contudo, sabe-se que diversos itens imprescindíveis à boa prática experimental com animais pesam no orçamento anual de um departamento ou instituto de psicologia: alimento, eventuais cuidados veterinários, manutenção de equipamentos e mão-de-obra com limpeza, controle de procriação, extermínio, etc.

\section{A Alternativa Tecnológica}

Por causa das dificuldades éticas, legais e financeiras relacionadas ao experimento com animais, docentes e pesquisadores da psicologia buscam alternativas na alta tecnologia (Krames, Graham \& Alloway, 1996; Oliveira, 1999). Uma recente pesquisa com mais de 600 faculdades públicas e privadas dos Estados Unidos (Green, 1999) assinalou uma duplicação do uso de simuladores computadorizados e uma triplicação do uso de material didático em CD-ROM, desde 1994. No Brasil, onde a alta tecnologia vem gradualmente se consolidando nas ciências sociais (Peres, 1997), é provável que tais recursos venham crescendo em popularidade.

Alguns programas de software se mostram economicamente acessíveis e bastante promissores para a utilização no ensino de graduação. Um desses programas é Sniffy, the Virtual Rat (Krames, Graham \& Alloway, 1996), que permite aos estudantes de psicologia explorar os princípios de modelagem e aplicar vários esquemas de reforço ao comportamento de um ratinho virtual. O programa inclui uma Caixa de Skinner e um registrador cumulativo virtuais, com possibilidade de se imprimirem os gráficos do condicionamento ou da extinção do comportamento de Sniffy. Certamente, o programa apresenta limitações, tais como a impossibilidade de se aplicar punição e de ocorrer saciação (pois presume-se que Sniffy esteja sempre privado de comida); mas, a verossimilhança e a facilidade de uso do programa têm gerado entusiásticos depoimentos de estudantes, ressaltando uma maior facilidade no domínio dos princípios básicos da aprendizagem (Krames, Graham \& Alloway, 1996; Oliveira, 1999).

\section{Esta Pesquisa}

Com a intensificação do debate internacional sobre as repercussões éticas e político-sociais do avanço científico, é oportuno que se investigue sobre como nos posicionamos, enquanto docentes e pesquisadores brasileiros, com relação às questões que acabamos de rever. É também oportuno que se faça um balanço da prática experimental, para ver se esta é congruente ou não com as atitudes que professamos. $\mathrm{O}$ presente estudo se propõe exatamente a isso, tomando como universo a Região Sul do Brasil, a segunda mais prolífica na pesquisa psicológica (Yamamoto, Souza \& Yamamoto, 1999) e uma das mais bem conceituadas no ensino de pós-graduação em psicologia do país (CAPES, 1998).

Procuramos estabelecer como os docentes de psicologia sul-brasileiros se sentem com relação ao uso de animais na pesquisa e no ensino de graduação, à legislação que regula essa prática e ao uso de simuladores computadorizados, com animais virtuais, no ensino de graduação. A fim de examinar se as atitudes correspondiam ou não à prática dos participantes, inquirimos também sobre os projetos de pesquisa animal (em andamento e concluídos) e as atividades didáticas atuais dos participantes.

Finalmente, seguindo o estudo pioneiro de Plous (1996), procuramos ver se algumas atitudes dos participantes poderiam ser explicadas a partir de certos dados demográficos. Em sua amostra representativa dos membros da APA, Plous encontrou uma proporção de homens significantemente maior do que de mulheres fortemente favoráveis ao uso de animais na pesquisa e no ensino de psicologia. As freqüências relativas de participantes de ambos os sexos que apoiavam o uso científico-didático de animais tendiam a cair, quanto mais recente era a data de obtenção do Ph.D. Esses resultados somam-se aos de outros estudos (e.g., Foundation for Biomedical Research e Pifer, Shimizu \& Pifer, conforme citados por Plous, 1996) para indicar que as mulheres, mais do que os homens, e os jovens, mais do que os idosos, tendem a adotar posições "politicamente corretas" em relação aos animais laboratoriais. Portanto, procuramos replicar esses resultados em nossa amostra sul-brasileira.

Indo além do que nos revela a literatura, procuramos ver se essas diferenças também se manifestariam quanto ao uso de simuladores computadorizados, com animais virtuais, no ensino de graduação, e acrescentamos mais duas variáveis explicativas: o tipo de instituição (privada vs. particular) e o nível de instrução dos participantes da pesquisa. A literatura existente não nos permitiu formular nenhuma hipótese específica a priori. 


\section{Método}

\section{Participantes}

A amostra consistiu de 19 professores da disciplina introdutória de psicologia experimental em instituições de ensino superior públicas $(n=5)$ e privadas $(n=14)$ dos estados de Paraná, Santa Catarina e Rio Grande do Sul. A Tabela 1 mostra os dados demográficos dos respondentes.

Tabela 1. Dados Demográficos dos Professores Respondentes $(N=19)$.

\begin{tabular}{lrrrr}
\hline \multicolumn{1}{c}{ Variáveis } & $\boldsymbol{n}$ & $\boldsymbol{\%}$ & Média & DP \\
\hline Idade & & & 36,21 & 6,885 \\
Gênero & 5 & 26,32 & & \\
Masculino & 14 & 73,68 & & \\
Feminino & & & & \\
\hline Titulação mais alta ${ }^{a}$ & 1 & 5,26 & \\
$\quad$ Graduação & 7 & 36,84 & \\
Especialização & 8 & 42,11 & \\
Mestrado & 1 & 5,26 & \\
Doutorado & 1 & 5,26 & \\
Pós-Doutorado & 3 & 15,79 & \\
\hline Tempo decorrido desde a titulação mais alta & & & \\
Menos de 1 ano & 3 & 15,79 & \\
1-2 anos & 5 & 26,32 & \\
3-4 anos & 2 & 10,53 & \\
5-6 anos & 4 & 21,04 & \\
9 anos ou mais & & & \\
\hline
\end{tabular}

Nota. ${ }^{a} n=18$

\section{Delineamento, procedimento e medidas}

O estudo foi essencialmente exploratório e não-experimental, reunindo análises descritivas e inferenciais comparativas e correlacionais. Através dos Conselhos Regionais de Psicologia dos três estados, foram listados todos os cursos de psicologia reconhecidos pelo Ministério da Educação e do Desporto. Em novembro de 1998, os professores da disciplina introdutória de psicologia experimental foram contactados, por telefone e/ou por carta, para participarem de um estudo "sobre o uso de animais reais e virtuais no ensino e na pesquisa da psicologia experimental." Além de explicar o propósito geral da pesquisa, a carta esclarecia sobre o caráter voluntário e sigiloso da participação. Anexo à carta, havia um questionário e um envelope auto-endereçado e pré-selado, para devolução do questionário preenchido.

As perguntas do questionário eram de múltipla escolha ou do tipo Sim/Não, algumas das quais eram derivadas do instrumento adotado por Plous (1996), para posterior comparação dos resultados. O contato pelo correio foi repetido em março e abril de 1999, com os participantes potenciais que ainda não haviam retornado o questionário preenchido.

Foram tabuladas as frequiências simples e percentuais das respostas. Os itens que refletiam as atitudes para com o uso de animais reais na pesquisa e no ensino, e de animais virtu- ais no ensino serviram de variáveis critérios para as análises estatísticas correlacionais e comparativas. As respostas a esses itens foram codificadas numa escala bipolar do tipo Likert, ancorada em 5 pontos $(-2=$ fortemente contra; $0=$ indeciso; 2 = fortemente favorável). Serviram como variáveis explicativas: Sexo (codificação alfanumérica), Instituição (codificação alfanumérica), Idade (em anos) e Instrução, codificada numa escala Likert de 5 pontos ( $0=$ graduação; 4 = pós-doutorado).

\section{Resultados}

A Tabela 2 apresenta as atitudes dos participantes quanto ao uso de animais na pesquisa psicológica. O nível médio de concordância com o uso de animais laboratoriais na pesquisa foi relativamente elevado $(M=1,26)$, com cerca de $74 \%$ dos respondentes declarando-se favoráveis, e os demais, fortemente favoráveis a essa prática. Os participantes também se mostraram bastante consensuais quanto à crença de que a pesquisa animal é necessária para o progresso da psicologia $(89,47 \%)$, e um pouco menos consensuais $(68 \%)$

Tabela 2. Atitudes para com o Uso de Animais na Pesquisa Psicológica ( $N$ $=19$ ).

\begin{tabular}{|c|c|c|c|c|}
\hline Ítem & $n$ & $\%$ & Média & DP \\
\hline \multicolumn{3}{|c|}{ Atitude para com o uso de animais na pesquisa } & 1,26 & 0,452 \\
\hline Fortemente favorável & 5 & 26,32 & & \\
\hline Favorável & 14 & 73,68 & & \\
\hline Indeciso & 0 & 0,00 & & \\
\hline Contra & 0 & 0,00 & & \\
\hline Fortemente contra & 0 & 0,00 & & \\
\hline \multicolumn{5}{|c|}{ Crê na necessidade da pesquisa animal para o progresso da psicologia } \\
\hline Sim & 17 & 89,48 & & \\
\hline Não & 1 & 5,26 & & \\
\hline Indeciso & 1 & 5,26 & & \\
\hline \multicolumn{5}{|c|}{ Crê que o financiamento da pesquisa animal deveria... } \\
\hline aumentar & 5 & 26,32 & & \\
\hline ser mantido & 13 & 68,42 & & \\
\hline diminuir & 1 & 5,26 & & \\
\hline \multicolumn{5}{|l|}{ Razões que justificam a resposta anterior ${ }^{\mathrm{a}}$} \\
\hline Teóricas & 11 & 57,89 & & \\
\hline Financeiras & 0 & 0,00 & & \\
\hline Éticas & 4 & 21,05 & & \\
\hline Outras & 5 & 26,32 & & \\
\hline \multicolumn{5}{|c|}{ Crê que as leis que controlam a pesquisa animal no Brasil são ${ }^{b} \ldots$} \\
\hline fracas e deveriam ser mais rígidas & 9 & 47,37 & & \\
\hline adequadas e deveriam ser mantidas & 2 & 10,53 & & \\
\hline $\begin{array}{l}\text { excessivas e deveriam ser mais } \\
\text { brandas }\end{array}$ & 0 & 0,00 & & \\
\hline Desconhece tais leis & 7 & 36,84 & & \\
\hline $\begin{array}{l}\text { Atitude para com a avaliação da dor de } \\
\text { animais experimentais }\end{array}$ & & & 0,842 & 1,068 \\
\hline Fortemente favorável & 5 & 26,32 & & \\
\hline Favorável & 9 & 47,37 & & \\
\hline Indeciso & 3 & 15,79 & & \\
\hline Contra & 1 & 5,26 & & \\
\hline Fortemente contra & 1 & 5,26 & & \\
\hline
\end{tabular}

Nota. ${ }^{\text {a }}$ somente um respondente indicou mais de uma resposta; ${ }^{\mathrm{b}} n=18$. 
quanto à manutenção do atual nível de financiamento dessa modalidade de pesquisa. Mais da metade justificou sua posição sobre o financiamento com bases teóricas. Quanto à política de trato dos animais, a amostra se posicionou bastante favorável à avaliação do grau de sofrimento dos animais selecionados para participarem da pesquisa psicológica, embora boa parcela $(36,84 \%)$ tenha admitido não conhecer a lei que dispõe sobre os crimes ambientais.

Tabela 3. Atitudes para com o Uso de Animais Reais e Virtuais no Ensino de Graduação $(N=19)$

\begin{tabular}{lrrcc}
\hline Ítem & $\boldsymbol{n}$ & $\boldsymbol{\%}$ & Média & $\boldsymbol{D P}$ \\
\hline Atitude para com o uso de animais reais & & & 1,00 & 0,817 \\
no ensino de graduação & & & & \\
$\quad$ Fortemente favorável & 3 & 15,79 & & \\
$\quad$ Favorável & 15 & 78,95 & & \\
Indeciso & 0 & 0,00 & & \\
Contra & 0 & 0,00 & & \\
$\quad$ Fortemente contra & 1 & 5,26 & \\
\hline Considera que os animais são tratados & $\ldots$ \\
muito bem & & & & \\
bem & 2 & 10,53 & & \\
mal & 10 & 52,63 & & \\
muito mal & 3 & 15,79 & & \\
Indeciso & 1 & 5,26 & & \\
\hline Atitude para com o uso de animais & 2 & 10,53 & & \\
virtuais no ensino de graduação & & & 0,44 & 1,199 \\
\hline Fortemente favorável & & & & \\
Favorável & 3 & 15,79 & & \\
Indeciso & 7 & 36,84 & & \\
Contra & 2 & 10,53 & & \\
Fortemente contra & 4 & 21,05 & & \\
\hline
\end{tabular}

Nota. ${ }^{\mathrm{a}} n=18 ;{ }^{\mathrm{b}} n=17$.

A Tabela 3 resume os dados sobre as atitudes dos participantes quanto ao uso de animais reais e virtuais no ensino de psicologia. Novamente, os participantes foram bastante consensuais em seu apoio ao uso de animais no ensino de psicologia, embora mais de $20 \%$ da amostra tenha admitido que os animais laboratoriais eram mal ou muito mal cuidados, e mais de $10 \%$ tenha expressado dúvidas a esse respeito. Já a questão do uso de animais virtuais, através de simuladores computadorizados, suscitou certa controvérsia entre os respondentes, dois dos quais se abstiveram de responder. A resposta modal $(36,84 \%)$ foi favorável, mas houve também respostas distribuídas em todos os demais níveis.

Como revela a Tabela 4 , no tocante à prática de pesquisa, os dados mostram que $84,21 \%$ da amostra não possuía projeto em andamento, e uma porcentagem igualmente elevada não havia publicado $(84,22 \%)$ ou apresentado em eventos $(78,95 \%)$ qualquer trabalho científico com animais nos últimos 4 anos. Em contraste, quase 73,68\% informou utilizar atividades didáticas com animais, ainda que $36,84 \%$ tenha também indicado que a abolição dessa prática vinha sendo discutida em seu departamento ou instituto. Já as atividades didáticas com animais virtuais, por meio de simuladores computadorizados, parecem apenas estar sendo introduzidas nas instituições participantes $(10,52 \%)$.
Tabela 4. Práticas com Animais em Pesquisa e Ensino de Psicologia $(N=$ 19).

\begin{tabular}{|c|c|c|}
\hline Ítem & $n$ & $\%$ \\
\hline \multicolumn{3}{|c|}{ Possui algum projeto de pesquisa animal em andamento } \\
\hline Sim & 3 & 15,79 \\
\hline Não & 16 & 84,21 \\
\hline \multicolumn{3}{|c|}{$\begin{array}{l}\text { Relatos de pesquisa animal apresentados em eventos nos últimos } \\
\text { quatro anos }\end{array}$} \\
\hline Nenhum & 15 & 78,95 \\
\hline $1-2$ & 0 & 0,00 \\
\hline $3-4$ & 3 & 15,79 \\
\hline $5-6$ & 0 & 0,00 \\
\hline $7-8$ & 0 & 0,00 \\
\hline Mais de 8 & 1 & 5,26 \\
\hline \multicolumn{3}{|c|}{ Relatos de pesquisa animal publicados nos últimos quatro anos } \\
\hline Nenhum & 16 & 84,22 \\
\hline $1-2$ & 1 & 5,26 \\
\hline $3-4$ & 1 & 5,26 \\
\hline $5-6$ & 0 & 0,00 \\
\hline $7-8$ & 0 & 0,00 \\
\hline Mais de 8 & 1 & 5,26 \\
\hline \multicolumn{3}{|c|}{ Usa animais no ensino de graduação em psicologia } \\
\hline Sim & 14 & 73,68 \\
\hline Não & 5 & 26,32 \\
\hline \multicolumn{3}{|c|}{$\begin{array}{l}\text { Instituição discute a possível abolição do uso de animais no ensino de } \\
\text { graduação em psicologia }\end{array}$} \\
\hline Sim & 7 & 36,84 \\
\hline Não & 12 & 63,16 \\
\hline \multicolumn{3}{|c|}{$\begin{array}{l}\text { Usa animais virtuais, através de simuladores computadorizados, no } \\
\text { ensino de graduação em psicologia }\end{array}$} \\
\hline Sim & 2 & 10,52 \\
\hline Não & 17 & 89,48 \\
\hline
\end{tabular}

A Tabela 5 apresenta dados explicativos de algumas atitudes em função de fatores demográficos. Destaca-se que mais homens $(60 \%)$ do que mulheres $(14,29 \%)$ se apresentaram fortemente favoráveis ao uso de animais na pesquisa psicológica. Os dados revelam ainda que quanto mais jovens os participantes, mais favorável a atitude para com o uso de animais reais no ensino de graduação; e quanto maior o nível de instrução, mais favorável a atitude dos participantes para com o uso didático de animais virtuais. Uma correlação negativa marginal foi também encontrada entre nível de instrução e atitude favorável para com o uso de animais reais no ensino de psicologia. Docentes de instituições públicas também se mostraram mais favoráveis que seus pares de instituições privadas quanto ao uso de animais virtuais no ensino de psicologia, embora esse resultado deva ser interpretado com cautela, pois havia apenas 5 docentes de instituições públicas.

\section{Discussão}

Acompanhando o debate internacional sobre o uso de animais laboratoriais no campo psi, examinamos no presente estudo as atitudes dos docentes de psicologia experimental sul-brasileiros quanto à ética, a legislação e a política de 
Tabela 5. Atitudes em Função de Variáveis Demográficas $(N=19)$.

\begin{tabular}{lllc}
\hline $\begin{array}{l}\text { Variáveis } \\
\text { Demográficas }\end{array}$ & Atitudes & Teste & Resultado \\
\hline Sexo & $\begin{array}{l}\text { Uso de animais reais na } \\
\text { pesquisa }\end{array}$ & $\begin{array}{l}\text { Qui } \\
\text { Quadrado }\end{array}$ & 3,97 \\
\hline Idade & $\begin{array}{l}\text { Uso de animais reais no ensino } \\
\text { de graduação em psicologia }\end{array}$ & $\begin{array}{l}\text { Correlação } \\
\text { de Pearson }\end{array}$ & $-0,46$ \\
\hline Instrução & $\begin{array}{l}\text { Uso de animais reais no ensino } \\
\text { de graduação em psicologia }\end{array}$ & $\begin{array}{l}\text { Correlação } \\
\text { de Pearson }\end{array}$ & $-0,44 \dagger$ \\
& $\begin{array}{l}\text { Uso de animais virtuais no } \\
\text { ensino de graduação em }\end{array}$ & $\begin{array}{l}\text { Correlação } \\
\text { de Pearson }\end{array}$ & 0,47 \\
& psicologia & & 2,21 \\
\hline Instituição & $\begin{array}{l}\text { Uso de animais virtuais no } \\
\text { ensino de graduação em }\end{array}$ & Teste $t$ & \\
& psicologia & & \\
\hline
\end{tabular}

Nota. ${ }^{\dagger} p=0,06$; os demais valores são significativos com $p<0,05$.

financiamento da pesquisa e do ensino com animais laboratoriais, e quanto ao uso alternativo de simuladores computadorizados. O papel de fatores demográficos na explicação de algumas dessas atitudes foi testado e as atuais práticas de pesquisa e ensino foram comparadas com as atitudes autopercebidas dos participantes, conforme se discute a seguir.

\section{Atitudes para com o uso/políticas aplicadas ao uso de animais na pesquisa psicológica}

Claramente, os docentes sul-brasileiros unanimemente apoiam o uso de animais na pesquisa psicológica, não havendo entre os respondentes sequer um que se mostrasse contrário, ou ao menos indeciso, sobre a questão. Tal unanimidade compremeteu um pouco a análise estatística dos fatores demográficos hipoteticamente relacionados à atitude para com o uso de animais na pesquisa, mas ainda assim os dados revelam que os homens, mais do que as mulheres, estão dispostos a apoiar a pesquisa animal. Esses resultados corroboram relatos anteriores de diferentes atitude entre os sexos (Plous, 1996). Por outro lado, o unânime apoio dos sul-brasileiros a esse tipo de pesquisa contrasta com a resistência de uma pequena, mas considerável parcela da classe docente universitária em países norte-americanos (Plous, 1996) e europeus (Rowan \& Loew, 1995; Thomas \& Blackman, 1992). Por exemplo, enquanto quase $90 \%$ dos sul-brasileiros selecionados indicaram ser a pesquisa animal necessária para o progresso da psicologia, $31 \%$ de uma amostra dos Estados Unidos (Plous, 1996) viam a pesquisa animal como desnecessária, ou tinham dúvidas a respeito do assunto.

Coerente com as atitudes relatadas quanto à pesquisa animal, a posição dominante dos sul-brasileiros é favorável à manutenção do atual nível de financiamento dessa pesquisa, principalmente por razões teóricas. Por outro lado, parece estar havendo um despertamento quanto à política de trato dos animais laboratoriais, como se revela numa atitude bastante favorável à avaliação do grau de sofrimento dos animais selecionados para participarem em pesquisa psicológica. Esse resultado harmoniza-se com a indicação de quase metade dos respondentes de que as atuais leis brasileiras se- riam fracas e carentes de maior rigor no controle da pesquisa animal. Na Grã-Bretanha, Canadá e Países Baixos, por exemplo, antes de ser implementado, qualquer projeto de pesquisa psicológica animal deve passar por uma avaliação da dor envolvida no procedimento experimental, através de instrumentos objetivos que levam em conta as diferentes espécies (Orlans, 1993).

Portanto, os resultados indicam que dificilmente se poderia alegar que o apoio consensual dos sul-brasileiros à pesquisa animal reflete um descaso pelo bem-estar dos animais laboratoriais. Contudo, é preocupante que $36,84 \%$ da amostra tenha declarado desconhecer a lei brasileira que controla a pesquisa animal. Em parte, talvez isso se explique pelo fato de que a atual lei (i.e., Lei Federal 9.605/98) houvera sido promulgada recentemente, na data em que foram coletados os dados. Por outro lado, é também possível que esse resultado esteja apontando para a necessidade de melhor se informar a comunidade científica sobre aspectos legais da profissão.

\section{Atitudes para com o uso de animais reais e virtuais no ensino de psicologia}

Como na pesquisa psicológica, os sul-brasileiros se mostram consensualmente favoráveis ao uso de animais no ensino de graduação em psicologia. Os dados também mostram que o nível de apoio ao emprego de animais no ensino varia em função da idade, pois quanto menor a idade dos docentes, mais favoráveis as suas atitudes. Esse padrão de resultados é oposto ao que se esperava com base nos dados norteamericanos (Plous, 1996), embora seja importante lembrar que naquela amostra todos eram doutores e o apoio ao uso de animais no ensino tendia a cair quanto mais recente era a obtenção do doutorado (ou, presumivelmente, quanto mais jovens eram os participantes). Na presente amostra, o grau de instrução dos participantes foi disperso e revelou uma correlação negativa marginal com as atitudes. Em conjunto, os dados parecem sugerir relações bem complexas entre a idade, o grau de instrução acadêmica e as atitudes para com o uso didático de animais. Entre os sul-brasileiros, o avanço da idade pode estar tornando as atitudes cada vez menos favoráveis ao uso didático de animais através de uma visão mais crítica que se desenvolve com o avanço do grau de instrução. Novos estudos, com amostras bem maiores, seriam necessários para analisar essas relações e o possível papel mediador do grau de instrução.

A atitude favorável ao uso de animais no ensino é, de certo modo, surpreendente, quando se leva em conta que mais de 30\% da amostra admitiu que os animais laboratoriais eram mal ou muito mal cuidados, ou ao menos tinha dúvidas a esse respeito. Em conjunto com o apoio dos sul-brasileiros a políticas de controle do sofrimento animal, esses dados sugerem que as atividades didáticas com animais são bem-vindas, mas há certa preocupação com o modo como esses animais vêm sendo tratados.

Quanto à questão do uso didático de animais virtuais, através de simuladores computadorizados, certa controvér- 
sia parece existir, como indicam a dispersão das respostas e a abstinência de 2 respondentes. Os dados levam a crer que o entusiasmo dos sul-brasileiros pelos animais virtuais, ainda que moderado, é relativamente menor do que pelos animais reais. Dentre os fatores demográficos testados, tanto o tipo de instituição como o nível de instrução dos docentes são, ao menos em parte, responsáveis pela variância nas atitudes para com o uso de animais virtuais no ensino. Embora escassos na presente amostra, os docentes de instituições públicas são significativamente mais favoráveis do que seus pares de instituições particulares. E quanto maior o grau de instrução dos participantes, mais favoráveis suas atitudes para com o uso de animais virtuais no ensino de graduação em psicologia.

Segundo Peres (1997), as atitudes dos docentes de ciências sociais para com a nova tecnologia informática no ensino variam em função do nível de familiaridade que eles têm com as ferramentas tecnológicas, em geral. Na medida que o aumento do grau de instrução acadêmica presumivelmente favorece a familiaridade com as ferramentas tecnológicas, faz sentido a correlação positiva encontrada entre o nível de instrução e as atitudes favoráveis dos docentes sul-brasileiros para com o uso didático de animais virtuais. Por outro lado, como indicam Guimarães e Caruso (1996), no Brasil, as instituições de ensino superior públicas concentram bem maior número de doutores do que as instituições privadas. Assim, na medida que os docentes com maior nível de instrução se interessam mais pelas atividades didáticas computadorizadas, e esses docentes se concentram mais nas instituições públicas do que nas privadas, os resultados do presente estudo são bastante consistentes.

\section{Práticas com animais laboratoriais}

Um dos objetivos do estudo foi comparar as práticas e as atitudes auto-percebidas dos docentes sul-brasileiros quanto ao uso de animais reais e virtuais na psicologia experimental, a fim de estabelecer pontos coerentes e incoerentes. No tocante à prática de pesquisa animal, os dados revelam uma baixa produtividade nos últimos 4 anos. Cabe, portanto, a pergunta: Por que os cientistas sul-brasileiros estão se esquivando de fazer pesquisa com animais, se, paradoxalmente, eles se mostram tão favoráveis a esse tipo de atividade, e a julgam necessária para o avanço da psicologia?

A falta de recursos financeiros dificilmente justificaria a baixa produtividade na pesquisa psicológica animal, visto que $68,42 \%$ da amostra optou pela manutenção dos atuais níveis de financiamento. Igualmente, os dados pouco sustentam a hipótese de Hunziker (1995) de que a reduzida freqüência dessa pesquisa no Brasil estaria sendo teoricamente motivada por uma nova prioridade mentalista e humanista no campo da psicologia experimental. Pois, a maior parte da amostra pareceu discordar que o dinheiro usado na pesquisa animal seria melhor empregado em pesquisas com seres humanos, como requer o argumento de Hunziker. Além disso, os respondentes indicaram que a manutenção dos gastos com a pesquisa animal é justificável teoricamente.
A hipótese de que a pesquisa psicológica experimental brasileira tenha atravessado uma mudança paradigmática $d e$ facto é também pouco amparada por dados apresentados por Vieira (1998). Dentre 333 pesquisadores de psicologia catalogados em referências nacionais, Vieira encontrou somente $42(12,6 \%)$ que indicavam a psicologia cognitiva como área de interesse. E, dentre os programas de pós-graduação strictu sensu em todo o país, ela identificou apenas dois que tinham a psicologia cognitiva como área de concentração, sendo ambos fora da Região Sul. Por outro lado, ao inspecionarmos o Diretório de Pesquisadores da Psicologia Brasileira (Feitosa, Zannon \& Günther, 1997), constatamos que a psicologia experimental brasileira continua bastante interessada na pesquisa animal. Dos nove pesquisadores que se identificaram como atuantes nessa área, cinco descreveram seus interesses com termos bem característicos (comportamento animal) ou, ao menos, compatíveis com a pesquisa animal (equivalência de estímulos, comportamento induzido por esquemas, psicofarmacologia, etc.).

Portanto, parece-nos que a diminuta produtividade na pesquisa animal não reflete diretamente a falta de dinheiro, mudança de orientação teórica e nem atitudes resistentes. Antes, é possível que, na Região Sul do país, os psicólogos experimentais estejam pouco produtivos em pesquisa, talvez por se dedicarem mais a atividades de ensino, como seria de se esperar em uma amostra com mais de $40 \%$ de graduados e especialistas, atuando predominantemente em instituições de ensino privadas.

No tocante a atividades práticas com animais no ensino de graduação, os dados mostram que os sul-brasileiros são bem mais coerentes com suas atitudes auto-percebidas. Quase $74 \%$ da amostra informou utilizar atividades didáticas com animais, o que se aproxima da frequiência relativa de docentes com atitudes favoráveis a essa prática. Portanto, as disciplinas introdutórias de psicologia experimental no sul do Brasil parecem estar desenvolvendo práticas bem harmoniosas com as disposições conscientes dos docentes. Contudo, vale notar que $36,84 \%$ da amostra indicou que a abolição dessa prática tem sido discutida em seu departamento ou instituto, talvez como reflexo da preocupação sobre o tratamento dos animais, expressa por significativa parcela da amostra.

Embora muitas instituições representadas estejam debatendo sobre a continuidade do uso pedagógico de animais, os dados mostram que o uso alternativo de simuladores computadorizados, com animais virtuais, está apenas sendo introduzido. É razoável se esperar um aumento desse índice nos próximos anos, já que boa parcela da amostra se revelou favorável à prática laboratorial informatizada, e as vantagens financeiras, éticas e pedagógicas dessa prática estão começando a ser verificadas e divulgadas (Krames, Graham \& Alloway, 1996; Oliveira, 1999). Por outro lado, é também provável que a opção por animais virtuais não exclua o uso de animais reais, especialmente nos casos em que a simulação computadorizada deixa de refletir o "mundo real" que algumas atividades requerem. Parece-nos que os softwares com animais virtuais surgem como uma opção inteligente e 
ética, apenas na medida que cumprem os mesmos objetivos didáticos das tradicionais atividades laboratoriais (replicação de experimentos clássicos, atividades demonstrativas), sem envolver o enjaulamento e a manipulação de animais vivos.

\section{Conclusão}

Nosso estudo evidencia que as práticas laboratoriais dos docentes de psicologia sul-brasileiros nem sempre refletem suas atitudes, ao contrário do que tende a ocorrer em países desenvolvidos da Europa e da América do Norte. No tocante à pesquisa, os sul-brasileiros consensualmente se posicionam a favor do uso de animais; contudo, admitem produzir muito pouco em pesquisa animal. Já no ensino de graduação, o uso efetivo de animais é bem mais congruente com as atitudes expressas para com essa prática, embora haja prenúncios de mudança. Entre os animais reais e virtuais, as atitudes e práticas pedagógicas claramente se concentram nos primeiros. Mas, é possível que a crescente qualificação dos docentes e a própria demanda por uma política mais restritiva das práticas experimentais com animais reais provoquem uma busca mais intensa pela alternativa tecnológica, nos próximos anos, equilibrando um pouco mais o uso didático de animais reais e virtuais.

\section{Referências}

American Psychological Association. (1992). Guidelines for ethical conduct in the care and use of animals. Washington, DC: Autor.

APA Science Directorate. (s.d.). Research with animals in psychology. Disponível em: http://www.apa.org/science/animal2.html

Azar, B. (1999). Destructive lab attack sends a wake-up call. APA Monitor, 30(7), 16.

CAPES - Centro de Aperfeiçoamento de Pessoal de Nível Superior. (1998). Perfil da pós-graduação. Brasília, DF: Autor.

Conselho Federal de Psicologia (1995). Código de Ética. Psicologia - Legislação, 7, 94-111. Brasília, DF: Autor.

Diário Oficial da União, 13 de fevereiro de 1998, p. 1.

Feitosa, M. A. G., Zannon, C.M. L C. \& Günther, H. (1997). Diretório de Pesquisadores da Psicologia Brasileira. Número especial. Psicologia: Teoria e Pesquisa, 13.

Greek, R. \& Greek, J. (1999). Nonhuman primates are not furrylooking humans. Documento não-publicado. Disponível em: RGBRM@concentric.net.

Green, K. C. (1999). Rising use of technology. APA Monitor, 30(7), 37.

Guimarães, R. \& Caruso, N. (1996). Capacitação docente: O lado escuro da pós-graduação. Infocapes, 4(3), 5-18.

Hollis, K. L. (1997). Contemporary research on pavlovian conditioning: A "new" functional analysis. American Psychologist, 52, 956-965.

Hunziker, M. H. L. (1995). O uso de animais em psicologia: uma estratégia ultrapassada? Temas em Psicologia, 3, 65-71.

Krames, L, Graham, J. \& Alloway, T. (1996). Sniffy, the virtual rat. Version 4.5 for Windows. Pacific Grove, CA: Brooks/Cole Publishing.
Oliveira, E. A. de (1999). Simuladores computadorizados e condutas auto-percebidas de alunos e alunas de psicologia. Estudos de Psicologia, 16, 54-61.

Orlans, F. B. (1993). In the name of science: Issues in the responsible animal experimentation. New York: Oxford University.

Overmier, J. B. (1999). Response to lab-attack letter. APA Monitor, $30(9), 5$.

Peres, R. U. (1997). Novas tecnologias da informação: atitudes de docentes de ciências sociais e humanas. Dissertação de mestrado, Pontífica Universidade Católica de Campinas, Campinas.

Plous, S. (1996). Attitudes toward the use of animals in psychological research and education. American Psychologist, 51, 1167-1180.

Rivera, H. (1999). Violence against nonhuman animals. APA Monitor, 30(8), 48-49.

Rowan, A. N. \& Loew, F. M. (1995). The animal research controversy: Protest, process and public policy. North Grafton, MA: Tufts University, Center for Animals and Public Policy.

Thomas, G. V., \& Blackman, D. (1992). The future of animal studies in psychology. American Psychologist, 47, 1679.

Vieira, E. (1998). Em direção à psicologia cognitiva. Em Y. S. de Souza e M. L. T. Nunes (Orgs.), Família, organizações e aprendizagem: ensaios temáticos em psicologia (pp. 103-165). Porto Alegre: Pontifícia Universidade Católica.

Yamamoto, O. H., Souza, C. C. \& Yamamoto, M. E. (1999). A produção científica na psicologia: uma análise dos periódicos brasileiros no período 1990-1997. Psicologia: Reflexão e Crítica, 12, 549-565. 